\title{
A Comparative Study on the Preference for Delivery Process in Bangladesh
}

\author{
Tahsin Farzana Jisun, Md. Rasel Kabir
}

Lecturer, School of Business Studies, South East University, BANGLADESH

\begin{abstract}
The purpose of this study is to assess the current situation about caesarean births and natural births in Bangladesh. This study along with an objective of presenting the comparative analysis also examines the factors that influence women to take decision about their delivery. Statistical analyses based on face to face interviews with 110 pregnant women from government and private institution were performed to find out the dominant factors affecting women to choose their delivery process. Both bivariate analysis and binary logistic regression were used to identify the influential socioeconomic factors. This study attempted to seek out the factors that are responsible for women to take their decisions regarding the delivery process. The variables named living place, occupation, economic condition, education level and institution were found to be most significant.
\end{abstract}

Keywords: Caesarean section; Bangladesh; natural birth; factors; delivery process; pregnant women

\section{INTRODUCTION}

In this twenty-first century, there are two routes of birth; one is caesarean section or the other is vaginally through the birth canal. Caesarean section, also known as C- section is defined as the delivery of a fetus through surgical incisions made through the abdominal wall and the uterine wall. Once upon a time, there was no alternative to vaginal birth, except death. But in this new millennium, women do have a choice that has been provided by the wonders of modern technology and that alternative of vaginal birth is C- section. Over 500,000 women and girls die of complications related to pregnancy each year and over 99 percent of those deaths occur in developing countries like Bangladesh (Akanda, 2011). But now-a-days C-Section was considered as a life saving procedure for both the mother and the baby (Subedi). Maternal deaths have been declined 34\% during a period of 18 years worldwide (Kamal, 2013). Being a developing country, Bangladesh still has the highest Maternal Mortality Rate (MMR) (Kamal, 2013). Caesarean sections are usually done for the safety of the mother and the baby under conditions of maternal risk. The World Health Organization (WHO) stated in 1985 that there is no justification for any region to have a caesarean section rate higher than 10\% - 15\% (Gibbonsetel, 2010). Usually this recommended caesarean section rate is considered to be $15 \%$ suggested by WHO in 1985 (Mehtaetel). But in many countries, caesarean sections have increased beyond the recommended level of 15\% (Sufangetel). and Bangladesh is not an exception. From 1999 to 
2010, caesarean section increased from $0.7 \%$ to $12 \%$ in Bangladesh and this rate is higher in urban areas than in rural (Sarkeretel, 2012). Some women consider C- section is more advantageous than natural birth. They think that a C-section is a modern procedure to have a baby, involving the use of technology (Lowdon\& Derrick, 2002). Some women want to avoid the pain of vaginal birth and the operation has become so much safer now-a-days that the risks are relatively small in caesarean delivery (Khan \&Islam). Sometimes a caesarean birth is the only safe option when the baby is positioned side-to-side in the belly or the placenta is covering the cervix or when a woman has a history of physical complications or past difficult deliveries (Nazneenetel, 2011).Internal injuries can also be avoided by caesarean section delivery process. Moreover, a caesarean birth can be scheduled. So, most of the mothers suggest caesarean section. Though caesarean section delivery process is clean, quick and convenient, it has some disadvantages too. The most obvious problem is post operative recovery period. A surgery may be considered to be pain free but in the post operative period, mothers may feel discomfort and pain in the abdomen and elsewhere in the body. Caesarean mothers may not be able to involve themselves in the daily household chores for some weeks after the birth. Caesarean section creates problem on milking process. It is risky for the uterus; sometimes it can damage the uterus and may cause permanent infertility. High dose antibiotic and injection used during operation, which is bad for mother's health. On the other hand, normal delivery is safe and risk free. It does not need surgery. Babies born through normal delivery process have a lower risk of respiratory problems. Mothers who have experienced natural delivery are able to involve family life within few hours of delivery. Babies born vaginally are often calm, quiet and peaceful. It is also less expensive compared to caesarean birth procedure. In the context of Bangladesh, some families impose their decision of vaginal delivery to the women. And there are some misconceptions about normal delivery. Some mothers think; it is not good for the female organs. Natural birth has some disadvantages too. It is painful; fear and tension change the hormonal levels. Vaginal birth can take a long time. Another disadvantage is that, normal delivery is performed in front of strangers, unfamiliar surroundings that are very uncomfortable for women. Despite all these disadvantages, most of the women in Bangladesh still prefer natural birth process.

A few studies have been conducted for the preference of women of delivery settings. GuoSufang, Sabu S Padmadas, Zhao Fengmin, James J Brown, R William Stones had studied the delivery settings in China. MorshedaBanu and Hashima E Nasreen(2011) sought out the factors that influenced the performance of delivery centers in urban slums of Bangladesh. In 2011, Md. Abdus Salam Akanda showed in his study "Demand for Institutional Delivery in Bangladesh: An application of Production Function", the factors especially household income and media influencing the demand for institutional delivery in Bangladesh. S.M Mostofa Kamal (2013) examined the preference of institutional delivery and caesarean section in Bangladesh. For this study, he used data from the nationally-representative 2007 Bangladesh Demographic and Health Survey. But in our study, we used the primary data from different public and private hospitals in Bangladesh .Our study will elaborate further by raising two possible research questions, namely (1) which delivery process the women of Bangladesh usually prefer now? (2) Which factors are responsible behind their preference? So our study reveals the current situation of delivery settings in Bangladesh. 


\section{Methodology}

Source of data: The study used primary data. The data were collected from different public and private hospitals in Bangladesh. 110 pregnant women were asked about their preference of delivery process and the factors affecting their preference. A simple random sampling was used to conduct the survey. The survey obtained the socio-economic factors that affect the decision of caesarean and normal delivery process.

Variables: The dichotomous dependent variable of this study is the type of delivery process that is C-section or normal delivery. Independent variables for this study are living place (urban and rural), age (15-25 and >25), education level (no education-primary, secondary-higher), income $(<=10000$ and $>10000)$, working status (housewife and service holder), institution (public and private). Also, the pregnant women were asked the factors that influence their decisions.

\section{Statistical Analysis}

All the analyses of this paper were performed by Statistical Package for Social Sciences (SPSS 16.0). Here we performed chi- square test first. Then the variables those found to be significant in chi-square were used to construct binary logistic regression model. We found that $69.1 \%$ women prefer natural delivery whereas $30.9 \%$ women prefer Caesarean delivery. The majority $(94.7 \%)$ of women from the rural area prefers normal delivery while $55.6 \%$ women from urban area prefer normal delivery. The study found $81 \%$ housewives prefer normal delivery and $69.2 \%$ working mothers prefer caesarean delivery. About $84.8 \%$ women having no education prefer normal delivery and about $54.5 \%$ women having education prefercaesarean delivery. The percentage of women who admitted into a private hospital prefers caesarean delivery is $75 \%$ and the percentage of women who admitted into the government hospital prefers normal delivery is $94.3 \%$.The study showed that the percentage of women whose family income is below or equal to $10000 /=$ prefer normal delivery is $92.3 \%$ and the percentage of women whose family income is above $10000 /=$ prefer C-section is $51.7 \%$. About $54.2 \%$ women who belong to the age group 15-25 years prefer C-section and about $87.1 \%$ women who belong to the age group above 25 years prefer normal delivery.

\section{Women who prefer normal delivery were asked about the factors that influence them to take their decision:}

About $97.4 \%$ of them reported normal delivery as safe and risk free. The analysis showed that there were $84.2 \%$ women considered this the best way to avoid the surgery. Approximately $15.8 \%$ women said that the maternal death is low in normal delivery process. Around $45 \%$ reported that they can easily involve in family chores within few hours of normal delivery. About $36.8 \%$ women were found post operative period is low in natural delivery. About $57.9 \%$ women reported that she and her family jointly decided to go with this process. The analysis found that $36.8 \%$ women considered it as a non-expensive process.

\section{Women who prefer caesarian delivery were asked about the factorsthat influence them to take their decision: \\ About $64.7 \%$ were found C-section as a modern and technology based process. About $40.5 \%$ women reported that they wanted to avoid vaginal pain during the delivery time. Approximately $76.5 \%$ women were found to adopt this setting due to physical complication. Around 35.3\% women reported that they had previous successful experience about $\mathrm{C}$-section.}




\section{Bivariate analysis}

Table 1: Results of Chi-square test to test significant variables

\begin{tabular}{|l|l|l|}
\hline Variables & P value & Decision \\
\hline Living place & 0.000 & significant \\
\hline Family decision & 0.500 & insignificant \\
\hline Institution & 0.000 & significant \\
\hline Occupation & 0.000 & significant \\
\hline Economic condition & 0.000 & significant \\
\hline Education level & 0.000 & significant \\
\hline
\end{tabular}

At $5 \%$ level of significance, it can easily be found from the chi-square table that the variables living place, institution, occupation, economic condition, education level are highly significant. The variable family decision is insignificant. After that, the significant variables were used to construct logistic regression model.

Table 2: Logistic regression analysis

\begin{tabular}{|l|l|l|l|}
\hline Variable & Coefficient & P value & Odds Ratio \\
\hline $\begin{array}{l}\text { Living place } \\
\text { Urban } \\
\text { Rural }^{*}\end{array}$ & 2.562 & 0.023 & 12.964 \\
\hline $\begin{array}{l}\text { Institution } \\
\text { Private Government* }\end{array}$ & 3.015 & 0.000 & 20.243 \\
\hline $\begin{array}{l}\text { Occupation } \\
\text { Service holder Housewife* }\end{array}$ & 2.1340 & 0.049 & 8.341 \\
\hline $\begin{array}{l}\text { Economic condition } \\
\text { Solvent } \\
\text { Insolvent* }\end{array}$ & 1.328 & 0.015 & 3.715 \\
\hline $\begin{array}{l}\text { Age group } \\
\text { Above 25 } \\
\text { Up to 25* }\end{array}$ & 1.745 & 0.034 & 5.618 \\
\hline $\begin{array}{l}\text { Education level } \\
\text { Secondary to higher } \\
\text { No education to primary* }\end{array}$ & 0.648 & 0.104 & 1.804 \\
\hline
\end{tabular}

The table showed that the women from the urban area prefer C-section more likely 12.964 times higher than the women from rural area. Likewise, the women admitted into a private hospital were found to prefer C-section more likely 20.293 times higher than the women in the government hospital. Also, we can say that the working mothers were found to prefer caesarean delivery more likely 8.341 times higher than the housewife.

The results of the bivariate logistic regression analysis showed that, at $5 \%$ level of significance, the variables living place, institution, occupation, economic condition, age group were found to have significant effect on caesarean delivery. The variable education level was found to be insignificant.

\section{CONCLUSION}

This quantitative cross- sectional study showed the current scenario of birth process in Bangladesh presenting with comparative analysis as percentage, rates, ratio. The analysis found the C-section rate is higher in urban $(29.1 \%)$ area than that of rural areas $(1.8 \%)$. This rate is also higher among service holders $(16.4 \%)$ than housewives $(14.5 \%)$. Bivariate analysis 
using a Chi-square test identified the significant variables: living place, institution, occupation, economic condition, age group that are highly associated with the preference of delivery process at $5 \%$ level of significance. One of the statistical analyses, logistic regression, provided an additional information regarding the preference of the delivery process where women preferred C-section how many times more likely than the women favoring natural birth depending on different dominant factors were found .From this study, it can easily be inferred that, it can easily be inferred that, though the Bangladeshi women are still preferring normal delivery process the caesarean rate is increasing significantly more than that of the previous rate. The statistical analysis showed that women were found to prefer C-section who were living in the urban area, admitted into private institution, educated with strong economic background, age above 25 and service holder as well.

\section{REFERENCES}

A.Mehta, Apers, L., Verstraelen, H., \&Temmerman, M. (n.d.). Trends in caesarean section rates at a maternity hospital in Mumbai, India.

Akanda, M. A. (2011). Demand for Institutional Delivery in Bangladesh: An Application of Household Production Function. Dhaka University Journal of Science.

Banu, M., \&Nasreen, H. E. (2011). Factors influencing the performance of delivery centres in urban slums of Bangladesh: A qualitative research. OIDA International Journal of Sustainable Development.

Davudsdttir, R. (2012). Anthropology of Childbirth-cross cultural approach.

Gibbons, L., Lauer, J. A., Belizan, J. M., Betran, A. P., Merialdi, M., \&Althabe, F. (2010). The Global Numbers and Costs of Additionally Needed and Unnecessary Caesarean Sections Performed per Year:Overuse as a Barrier to Universal Coverage. World Health Report (2010).

Kamal, S. M. (2013). Preference for Institutional Delivery and Caesarean Sections in Bangladesh.

Karim, M. R. (n.d.). Inappropriateness in Health Treatments and its Impact on economy: The Case of Caesarean Delivery in Bangladesh.

Khan, M. M., \& Islam, M. S. (n.d.). Collaborate public service delivery in Bangladesh: Does it really boost all- inclusive development?

Lowdon, G., \& Derrick, D. C. (2002). Caesarean section or vaginal birth? What difference does it make? AIMS Journal, Spring 2002, Vol 14 No 1

Main, E., Hopkins, D., \&Melsop, K. (2011). Cesarean Deliveries, Outcomes, and opportunities for change in California: Toward a Public Agenda for Maternity Care Safety and Quality.

Nazneen, R., Begum, R., \& Sultana, K. (2011). Rising Trend of Caesarean Section in a Tertiary Hospital Over a Decade.

Sarker, B. K., Higgins, J., Mridha, M. K., Ferdous, J., Dasgupta, S. K., Ahmed, S., et al. (2012). Caesarean Delivery in Urban Slums of Dhaka City:Indications and consequences. Manoshi Working Paper Series.

Subedi, S. (n.d.). RISING RATE OF CESAREAN SECTION - A YEAR REVIEW

Sufang, G., Padmadas, S. S., Fengmin, Z., Brown, J. J., \& Stones, R. W. (n.d.). Delivery settings and caesarean section rates in China. 


\section{Publish Online and Print Version Both}

ISSN Online: 2312-203X 